\title{
L-Proline: An Efficient and Selective Catalyst for Transamidation of Thioamides with Amines
}

Sadu Nageswara Rao, Darapaneni Chandra Mohan and Subbarayappa Adimurthy*

Academy of Scientific and Innovative Research, CSIR-Central Salt and Marine Chemicals Research Institute, GB Marg, Bhavnagar-364002, Gujarat, India

\begin{abstract}
L-Proline catalysed transthioamidation of primary thioamides with amines under solvent-free conditions has been described. The transthioamidation is compatible with wide range of amines with yields up to $97 \%$.
\end{abstract}

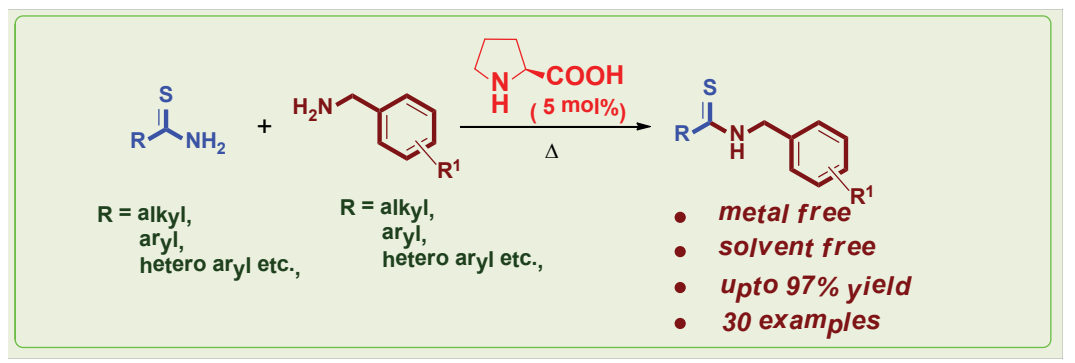

Keywords: Thioamides; Amines; L-Proline; Transthioamidation

\section{Introduction}

Thioamide is an important and useful functional group in both chemistry and biology. Thioamides are not only serve as versatile synthetic intermediates for the construction of pharmacologically important molecules containing nitrogen and sulfur heterocycles [1-7] but are also used as antitumor agents and enzyme inhibitors [8-10]. Thioamide based drugs such as ethionamide (ETH) and prothionamide (PTH) have been widely used for many years in the treatment of mycobacterial infections caused by Mycobacterium tuberculosis, M. leprae and $M$. avium complex infections [11,12]. Recently, functionalized-thioamide fluorescent dyes were also employed as metal ion sensors [13]. Diverse synthetic methods have been discovered for the synthesis of thioamides [14-23].

Transamidation is an attractive tool represents one of the most convenient and straightforward method, that would exchange the constituents of two different amide groups. Compared with transamidation of amides with amines, the corresponding transthioamidations are rarely reported with rather limited substrate scope $[24,25]$.

Most of the approaches for thioamide syntheses require transition metal catalysts to promote this transformation efficiently; also they suffer from inadequacies such as the expensive nature of catalyst, moisture and/or air sensitivity of Grignard reagents. Thus, the separation of metal catalyst from products, which is of particular importance for the synthesis of pharmaceuticals and fine chemicals because of their residual toxicity in the target compounds, is a central issue to consider. Moreover, transition metal-catalysed reactions also generate hazardous waste which is environmentally problematic and hence, should to be avoided wherever possible. These catalysts are active only in organic solvents. Therefore, the development of transthioamidations to access the desired amino substituted thioamides is of considerable interest. Furthermore, it is also highly desirable to develop environmentally benign chemical processes without requirement of any metal catalyst and solvent-free conditions.
Recently, organo catalysts have been employed in a variety of chemical transformations [26-30] and they dominate the natural world in triggering chemical reactions. Particularly, L-proline has received much attention due to its dual role as a ligand and catalyst [31-34]. In view of the above perceptions, the development of benign and metal-free transamidation procedures with high yield and selectivity is desirable. In continuation of our interest on the development of environmentfriendly transamidation catalysts [35-39], we wish to report a general L-proline-catalysed transthioamidation of primary amides with amines under solvent-free conditions [40]. To the best of our knowledge very rare reports available for the efficient transthioamidations under neat conditions [41].

For the initial studies, we chose thioacetamide la and benzyl amine $2 \mathrm{a}$ as substrates to explore the transthioamidations using L-proline as catalyst (Figure 1). Initially, when 1a and 2a were reacted with $5 \mathrm{~mol}$ $\%$ of L-proline catalyst in water at $130^{\circ} \mathrm{C}$ in a sealed tube, the desired transthioamidations derivative $3 \mathrm{a}$ was isolated in $10 \%$ yield after $36 \mathrm{~h}$ (Figure 1, entry 1). In ethanol as solvent $19 \%$ of 3 a was isolated (Figure 1 , entry 2). Shifting to other organic solvents (toluene, DMF, DMSO, NMP and DMA), the yield of the product was varied between $42 \%$ and 85\% (Figure 1, entries 3-7). To our delight, the reaction was also very facile under neat conditions at $130^{\circ} \mathrm{C}$ and gave $3 \mathrm{a}$ in $89 \%$ yield (Figure 1 , entry 8). Further, no improvement in the yield was observed either

*Corresponding author: Subbarayappa Adimurthy, Academy of Scientific and Innovative Research, CSIR-Central Salt and Marine Chemicals Research Institute, GB Marg, Bhavnagar-364002, Gujarat, India, Tel: 6860-2567760; E-mail: adimurthy@csmcri.org

Received April 18, 2016; Accepted May 09, 2016; Published May 17, 2016

Citation: Rao SN, Mohan DC, Adimurthy S (2016) L-Proline: An Efficient and Selective Catalyst for Transamidation of Thioamides with Amines. J Biomol Res Ther 5: 140. doi:10.4172/2167-7956.1000140

Copyright: (๑) 2016 Rao SN, et al. This is an open-access article distributed under the terms of the Creative Commons Attribution License, which permits unrestricted use, distribution, and reproduction in any medium, provided the original author and source are credited. 
Citation: Rao SN, Mohan DC, Adimurthy S (2016) L-Proline: An Efficient and Selective Catalyst for Transamidation of Thioamides with Amines. J Biomol Res Ther 5: 140. doi:10.4172/2167-7956.1000140

by lowering the reaction temperature or by increasing the catalyst loading (Figure 1, entries 9-12). Under the same conditions, without catalyst only $43 \%$ of desired product 3 a was isolated (Figure 1 , entry 13). Increasing the reaction temperature yield was not improved; decomposition of the product was observed (Figure 1, entries 14 and 15). Transthioamidation was not efficient with other amino acid catalysts tested (Figure 1, entries 16-19).

With the set of optimized reaction conditions in hand, we moved on to investigate the scope of this metal-free transthioamidation. A series of amines were subjected to the transthioamidation of thioacetamide under these conditions (Figure 2). The reaction was found to be very facile with both electron-rich and moderately electron-deficient amines and produced corresponding transthioamidation products $3 \mathrm{a}-3 \mathrm{f}$ in moderate to good yield (46-89\%). The transthioamidation was also efficient with variety of amines (alpha methyl, secondary benzyl, cyclic secondary, cyclohexyl, aryl alkyl and long chain aliphatic amines) and provided the corresponding products $3 \mathrm{~g}-3 \mathrm{n}$ in moderate to good yield (59\%-86\%). Similarly, transthioamidation of 2-(pyridin-2-yl) ethan-1amine also gave $85 \%$ yield of desired product (3o).

To show the synthetic utility of this method, a variety of thioamides and amines were subjected to these optimized conditions (Figure 3). As expected, the transthioamidation of thiobenzamide with variety of amines [benzyl amines (electron-neutral, -rich,-deficient), alkyl aromatic, aliphatic, cyclic secondary amines and hetero amines] provided the corresponding products $5 \mathrm{a}-5 \mathrm{~m}$ in moderate to good yields (33\%-82\%). Similarly, hetero amines like pyridin-2-ylmethanamine as well as heterothioamide were also gave the corresponding thioamidation products $5 \mathrm{n}$ and $5 \mathrm{o}$ in good yields. Based on our previous observations a plausible reaction mechanism has been proposed (Scheme 1). Initially, the reaction of thioamide with L-proline, generates the intermediate (I) through hydrogen bond formation. Subsequent addition of amine to the intermediate I, will give the desired transthioamidation product with the elimination of ammonia.

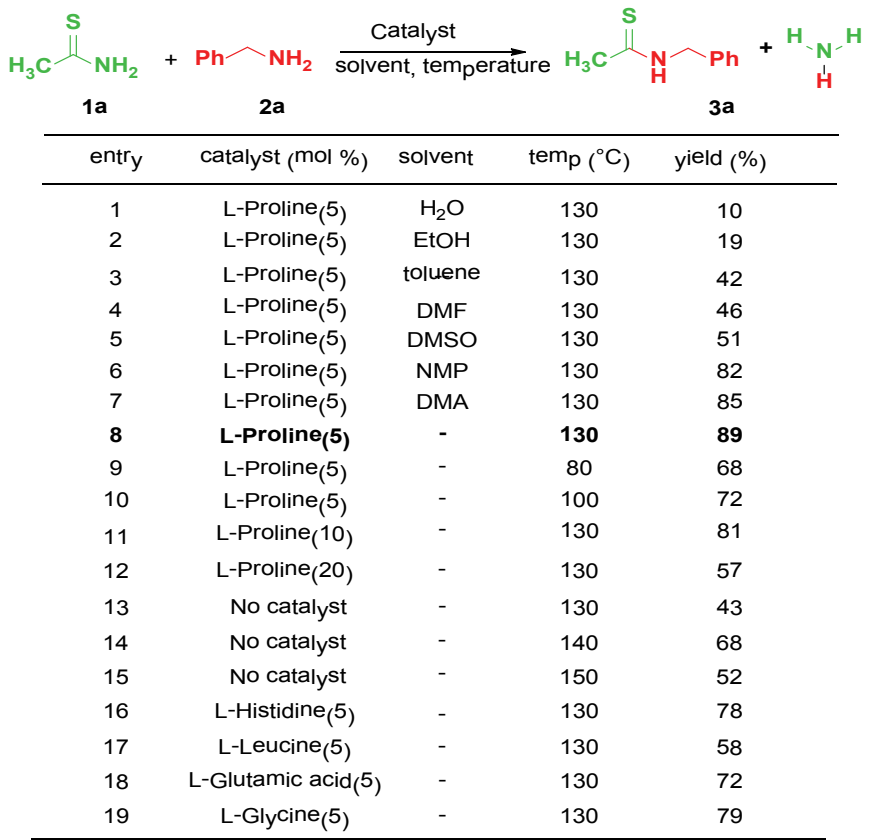

Figure 1: Optimization of reaction conditions ${ }^{\mathrm{a}}$ [ ${ }^{\mathrm{a}}$ Reaction conditions: 1a (2 $\mathrm{mmol}), 2 \mathrm{a}(2 \mathrm{mmol})$, solvent $(2 \mathrm{~mL})$, in a sealed tube, isolated yield].

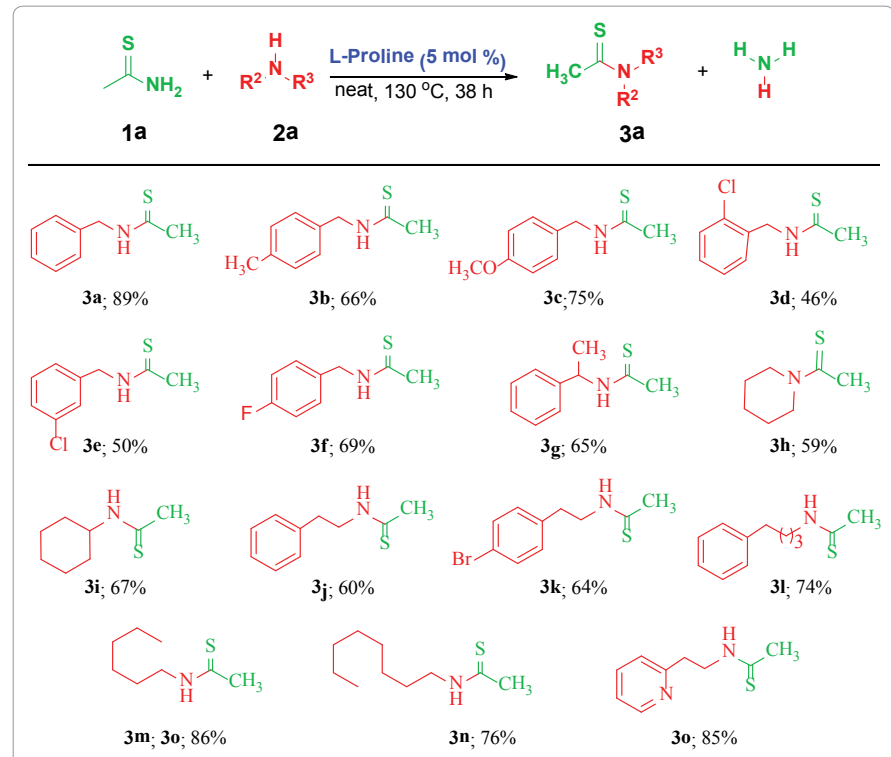

Figure 2: Scope for synthesis of thioamides using thioacetamide with different amines ${ }^{\text {a }}$ [ Reaction conditions: $1 \mathrm{a}(2 \mathrm{mmol}), 2 \mathrm{a}(2 \mathrm{mmol})$, L-proline $(11.5 \mathrm{mg})$, in a sealed tube, isolated yield.

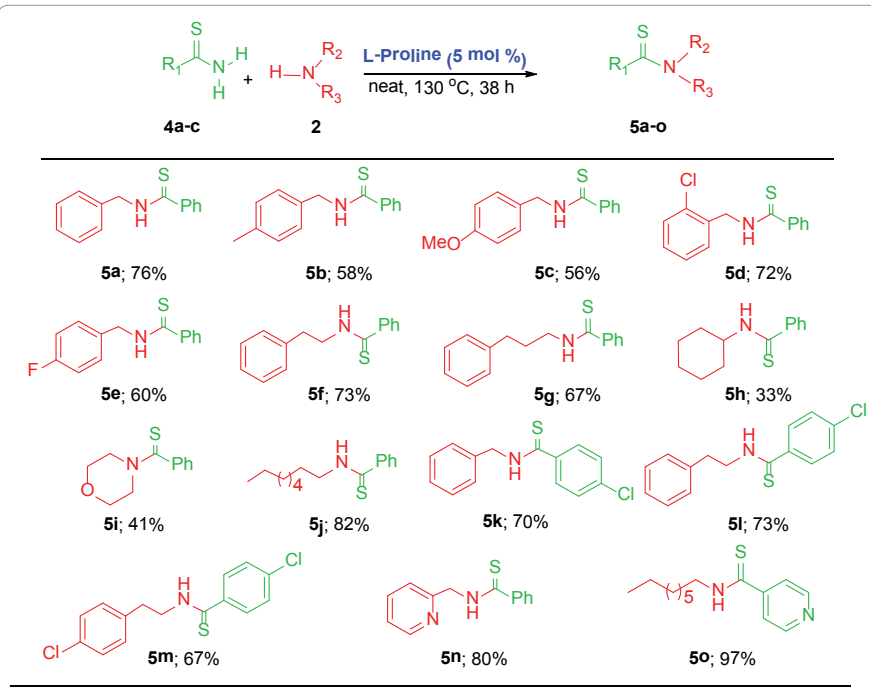

Figure 3: Scope for transamidation of thioamides with various thioamides and amines ${ }^{\mathrm{a}}$ [Reaction conditions: $1 \mathrm{a}(2 \mathrm{mmol}), 2 \mathrm{a}(2 \mathrm{mmol})$, L-Proline $(11.5 \mathrm{mg})$, in a sealed tube, isolated yield].

\section{Conclusion}

In summary, we have reported the synthesis of variety of thioamides using easily available L-proline catalysed transamidation of various thioamides with amines under neat conditions. With this method a variety of corresponding thioamides were obtained in good to excellent yields under solvent-free conditions.

\section{Acknowledgement}

CSIR-CSMCRI Communication No. 201/2015. We thank the "Analytical Discipline and Centralized Instrumental Facilities" for providing instrumentation facilities, S.N.R and D.C.M. are also thankful to CSIR and UGC, New Delhi for their fellowships. We thank DST, Government of India (SR/S1/OC-13/2011) and CSIR (CSC-0123) for the financial support. 
Citation: Rao SN, Mohan DC, Adimurthy S (2016) L-Proline: An Efficient and Selective Catalyst for Transamidation of Thioamides with Amines. J Biomol Res Ther 5: 140. doi:10.4172/2167-7956.1000140

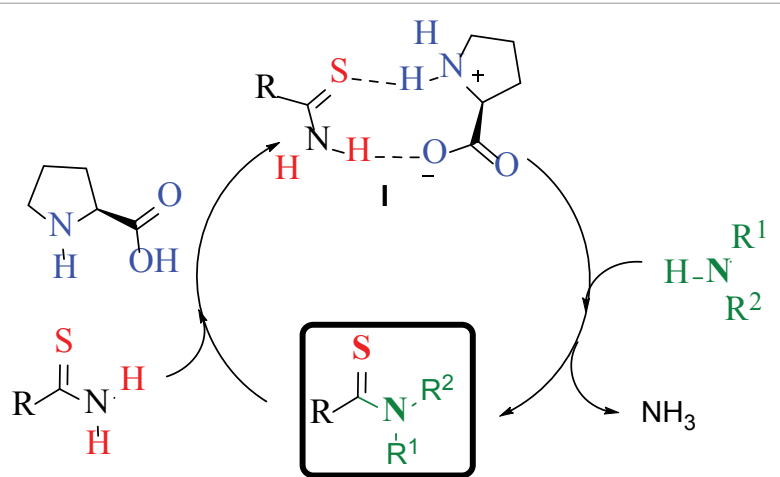

Scheme 1: Plausible reaction mechanisms.

\section{References}

1. Jagodzinski TS (2003) Thioamides as useful synthons in the synthesis of heterocycles. Chem Rev 103: 197-228.

2. Danilkina NA, Mikhailov LE, Ivin BA, (2006) Condensation of thioamides with acetylene carboxlic acid derivatives. Russian J Org Chem 42: 783-814.

3. Banala S, Süssmuth RD (2010) Thioamides in nature: in search of secondary metabolites in anaerobic microorganisms. Chem Bio Chem 11: 1335-1337.

4. Fang FG, Maier ME, Danishefsky SJ, Schulte G (1990) New routes to functionalized benzazepine substructures: a novel transformation of an alphadiketone thioamide induced by trimethyl phosphite. J Org Chem 55: 831-838.

5. Nicolaou KC, Lizos DE, Kim DW, Schlawe D, Noronha RG, et al. (2006) Total synthesis and biological evaluation of halipeptins $A$ and $D$ and analogues. J Am Chem Soc 128: 4460-4470.

6. Nicolaou KC, Dethe DH, Chen DYK (2008) Total syntheses of amythiamicins A, $\mathrm{B}$ and C. Chem Commun 2632-2634.

7. Padwa A, Beall LS, Heidelbaugh TM, Liu B, Sheehan SM (2000) A one-pot bicycloannulation method for the synthesis of tetrahydroisoquinoline systems. J Org Chem 65: 2684-2695.

8. Hu WP, Chen YK, Liao CC, Yu HS, Tsai YM, et al. (2010) Synthesis, and biological evaluation of 2-(4-aminophenyl)benzothiazole derivatives as photosensitizing agents. Bioorg Med Chem 18: 6197-6207.

9. Shi DF, Bradshaw TD, Wrigley S, McCall CJ, Lelieveld P, et al. (1996) Antitumor benzothiazoles 3. Synthesis of 2-(4-aminophenyl) benzothiazoles and evaluation of their activities against breast cancer cell lines in vitro and in vivo. J Med Chem 39: 3375-3384.

10. Stevens MFG, McCall CJ, Lelieveld P, Alexander P, Richter JA, et al. (1994) Structural Studies on Bioactive Compounds. Synthesis of Polyhydroxylated 2-Phenylbenzothiazoles and a Comparison of Their Cytotoxicities and Pharmacological Properties with Genistein and Quercetin. J Med Chem 37: 1689-1695.

11. Fajardo TT, Guinto RS, Cellona RV, Abalos RM, Dela EC, et al. (2006) A clinical trial of ethionamide and prothionamide for treatment of lepromatous leprosy. Am J Trop Med Hyg 74: 457-461.

12. Ajko DM, Nassos PS, Hadley WK (1987) Therapeutic implications of inhibition versus killing of Mycobacterium avium complex by antimicrobial agents. Antimicrob Agents Chemother 31: 117-120.

13. Hwang J, Choi MG, Eor S, Chang SK (2012) Fluorescence signaling of $\mathrm{Zr}^{4+}$ by hydrogen peroxide assisted selective desulfurization of thioamide. Inorg Chem 51: 1634-1639.

14. Cava MP, Levinson MI (1975) Thionation reactions of lawesson's reagents. Tetrahedron 41: 5061.

15. Zacharie B, Gilles Sauvé G, Penney C (1993) Enzymatic acylation and alkoxycarbonylation of $\alpha-$, xylo-, anhydro- and arabino-nucleosides. Tetrahedron 49: 10089-10098.

16. Curphey $T$ (2002) Thionation with the reagentc of phosphorus pentasulfide and hexamethyldisiloxane. J Org Chem 67: 6461-6473.

17. Bergman J, Pettersson B, Hasimbegovic V, Svensson PH (2011) Thionations using a P4S10-pyridine complex in solvents such as acetonitrile and dimethyl sulfones. J Org Chem 76: 1546-1553.
18. Shibahara F, Sugiura R, Murai T (2009) Direct thionation and selenation of amides using elemental sulfur and selenium and hydrochlorosilanes in the presence of amines. Org Lett 131: 3064-3067.

19. Szostak M, Aubé J (2009) Synthesis and rearrangement of a bridged thioamide Chem Commun pp: 7122-71224.

20. Zbruyev OI, Stiasni N, Kappe CO (2003) Preparation of thioamide building blocks via microwave-promoted three-component kindler reactions. J Comb Chem 5: 145-147.

21. Okamoto K, Yamamoto T, Kanbara T (2007) Efficient synthesis of thiobenzanilides by Willgerodt-Kindler reaction with base catalysts. Synlett 2687-2690.

22. Nguyen TB, Ermolenko LAMA (2012) Efficient and selective multicomponent oxidative coupling of two different aliphatic primary amines into thioamides by elemental sulphur. Org Lett 14: 4274-4277.

23. Sun $\mathrm{Y}$, Jiang $\mathrm{H}$, Wu W, Zeng $\mathrm{W}$, Li J (2014) Synthesis of thioamides via onepot A3-coupling of alkynyl bromides, amines, and sodium sulphide. Org Biomo Chem 12: 700-710.

24. Ji-Wei W, Ya-Dong W, Jian-Jun D, Hua-Jian X (2014) Benzoic acid-catalyzed transamidation reactions of carboxamides, phthalimide, ureas and thioamide with amines. Adv Synth Catal 356: 2429-2436.

25. Ojeda P, Gamba S (2015) Transamidation of thioacetamide catalyzed by $\mathrm{SbCl}_{3}$ Tetrahedron Letters 56: 4308-4311.

26. Dalko PI, Moisan L (2004) In the golden age of organocatalysis. Angew Chem Int Ed 43: 5138-5175.

27. MacMillan DWC (2008) The advent and development of organocatalysis Nature 455: 304-308.

28. Kotsuki $\mathrm{H}$, Ikishima $\mathrm{H}$, kuyama $\mathrm{A}$ (2008) Organocatalytic asymmetric synthesis using proline and related molecules. Part 2. Heterocycles 75: 757-797.

29. Bertelsen S, Jorgensen KA (2009) Organocatalysis-after the gold rush. Chem Soc Rev 38: 2178-2189.

30. Chai Z, Zhao G (2012) Efficient organocatalysts derived from simple chira acyclic amino acids in asymmetric catalysis. Catal Sci Technol 2: 29-41.

31. Coulthard G, Erb W, Aggarwal VK (2012) Stereocontrolled organocatalytic synthesis of prostaglandin PGF2 $\alpha$ in seven steps. Nature 489: 278-281.

32. Tanimoro T, Ueno M, Takeda K, Kirihata M, Tanimori S (2012) Proline catalyzes direct C-H arylations of unactivated arenes. J Org Chem 77: 7844-7847.

33. Tanimori S, Kobayashi Y, lesaki Y, Ozaki Y, Kirihata M (2012) Copper-catalyzed synthesis of substituted indazoles from 2-chloroarenes at low catalyst-loading. Org Biomol Chem 10: 1381-1387.

34. Nezhad AK, Sarikhani S, Shahidzadeh ES, Panahi F (2012) L-Proline-promoted three-component reaction of anilines, aldehydes and barbituric acids/malononitrile: regioselective synthesis of 5-arylpyrimido [4,5-b] quinoline-diones and 2-amino-4 arylquinoline-3-carbonitriles in water. Green Chem 14: 2876-2884.

35. Rao SN, Mohan DC, Adimurthy S (2013) L-Proline: an efficient catalyst for transamidation of carboxamides with amines. Org Lett 15: 1491-1493.

36. Rao SN, Mohan DC, Adimurthy S (2014) Chitosan: an efficient recyclable catalyst for transamidation of carboxamides with amines under neat conditions. Green Chem 16: 4122-4126.

37. Rao SN, Mohan DC, Adimurthy S (2015) H- $\beta$-zeolite catalyzed transamidation of carboxamides, phthalimide, formamides and thioamides with amines under neat conditions. RSC Adv 5: 95313-95317.

38. Mohan DC, Rao SN, Ravi C, Adimurthy S (2014) Copper(I) lodide Catalyzed Aerobic Oxidative C-N and C-S bond formations through C-H Activation: Synthesis of Functionalized Imidazo [1,2-a]pyridines. Asian J Org Chem 3: 609-614.

39. Ravi C, Mohan DC, Adimurthy S (2014) N-Chlorosuccinimide-promoted regioselective sulfenylation of imidazoheterocycles at room temperature. Org Lett 16: 2978-2981.

40. Fioravanti S, Parise L, Pelagalli A, Pellacani L, Trulli L (2015) Synthesis of $\mathrm{N}$-benzylthioacetamide (3a): In a sealed tube, $2.0 \mathrm{mmol}$ of $1 \mathrm{a}, 2.0 \mathrm{mmol}$ of $2 \mathrm{a}$ and L-proline $(11.5 \mathrm{mg})$ were stirred at indicated temperature for indicated reaction time (See Schemes 1-2 and Table 1). After being cooled to room temperature, the reaction mixture was extracted with $\mathrm{DCM}(3 \times 20 \mathrm{~mL})$. After removal of solvent, the crude reaction mixture left out was purified by recrystallization or silica gel (200-400 mesh) column chromatographic separation (dissolved in dichloromethane, eluted with dichloromethane and ethyl acetate). RSC Adv 5: 29312-29318.

41. Schlatter MJ (1942) The reaction between thioamides and primary amines. $J$ Am Chem Soc 64: 2722-2723. 